\title{
The Crabtree Effect and its Relation to the Petite Mutation
}

\author{
By R. H. DE DEKEN \\ Institut de Recherches du C.E.R.I.A., Brussels, Belgium
}

(Received 19 October 1965)

\begin{abstract}
SUMMARY
Some yeast strains are able to give rise to 'petite' mutants upon treatment with euflavine while some other strains do not give rise to cytoplasmic respiration-deficient mutants. Nevertheless euflavine mimics the effect of the petite mutation in those strains which are unable to give petite mutants. There is a correlation between the presence of the Crabtree effect in a yeast strain and its ability to give petite mutants.
\end{abstract}

\section{INTRODUCTION}

A non-Mendelian mutation that results in loss of capacity for respiration in yeast was described by Ephrussi, Hottinguer \& Chimenes (1949) and named 'petite' mutation. The mutation, which is irreversible, can be induced by some acridine dyes (Marcovitch, 1953). The simultaneous disappearance of several respiratory enzymes such as the cytochromes $a$ and $b$ and enzymes belonging to the tricarboxylic acid cycle, has been the object of numerous studies (Slonimski \& Ephrussi, 1949; Slonimski \& Hirsch, 1952; Slonimski, 1953a). The results of Linnane \& Still (1956) indicated that the modification of the amount of enzymes of the tricarboxylic acid cycle, such as succinic dehydrogenase, probably arises from secondary effects of the mutation on control mechanisms. In other words, the primary effect of the petite mutation is an inability to synthesize cytochromes of types $a$ and $b$.

The petite mutation has been studied almost exclusively in yeasts belonging to the genus Saccharomyces. A systematic study of the mutation in about twenty different strains of yeast, with euflavine as a mutagen, showed that some organisms were unable to give rise to petite mutants (De Deken, 1961 a). These results led to the following observations: (1) the synthesis of respiratory enzymes in strains which did not give petite mutants was inhibited by a mutagenic acridine such as euflavine (De Deken, 1961 b); (2) this inhibition, which was completely reversible, affects only the cytochromes $a$ and $b$, i.e. those which are affected by the petite mutation. In the present work, a more detailed study has been made of the inhibition of the synthesis of respiratory enzymes by euflavine and of the spectrum of mutability to petite among various yeasts. An attempt has been made to define the causes of this distinction between those yeasts which give petite mutants and those that are unable to give petite mutants. The analogy between the Crabtree effect and the action of mutagenic acridines, i.e. the inhibition of the synthesis of some cytochromes, as well as the importance of the Crabtree effect for yeast physiology, i.e. separation 
of the strains into fermentative and oxidative yeasts (see De Deken, 1966), suggested a correlation between the mutability to petite and ability to show the Crabtree effect. The results described below indicate that these two properties are indeed related.

\section{METHODS}

Growth medium. The medium contains $7 \cdot 6 \mathrm{~g}$. $\mathrm{KH}_{2} \mathrm{PO}_{4}, 5 \cdot 0 \mathrm{~g}$. of Difco yeast extract/l. distilled water, adjusted to $\mathrm{pH} 6 \cdot 0$. The carbon sources were: glucose $30 \mathrm{~g} . / 1$. or potassium lactate $0.1 \mathrm{M}$, or glycerol $0.1 \mathrm{M}$, or ethanol $10.0 \mathrm{~g} . / \mathrm{l}$.

Reagents. The euflavine was isolated from acriflavine by the method described by Albert (1951). The proflavine was a commercial sample (British Drug Houses).

Organisms. The organisms were the same as the one described previously (De Deken, 1966).

Spectroscopic observations. The yeast samples were suspended in glycerol and the centrifuged pellet was plated between two Pyrex windows. The thickness of the yeast layer was 1 or $2 \mathrm{~mm}$. The spectroscopic observation was made at the temperature of liquid air. For prolonged observation the sample was kept under vacuum in a metallic Dewar flask equipped with Pyrex windows. The sample was in thermal contact with the liquid air of the Dewar flask.

\section{RESULTS}

\section{Yeast strains unable to give petite mutants}

We noted previously (De Deken, 1961 $a$ ) that some yeast strains were apparently unable to give petite mutants upon treatment by euflavine. If the synthesis of the cytochromes of such strains is reversibly inhibited by euflavine-in other words, if euflavine is also able to reach the site of cytochromes synthesis in these strainsthen it is of interest to study such strains in order to find out what kind of genetic or physiological characteristic of the yeast strain is needed for the expression of the petite mutation. The ability of a strain to give petite mutants was tested in the following way. The yeast strain was grown with glucose as carbon source (see Methods) and treated with a known concentration of euflavine. The liquid cultures were incubated with shaking at the optimal temperature for each strain. The extinction of the culture was measured, and after five doublings of the optical density samples of the culture were plated on the same medium solidified with agar, but without euflavine. After growth, mutants colonies were identified by replication on a glucose medium and on a glycerol medium: respiration-deficient colonies were unable to grow on the glycerol medium. A strain was considered as unable to give petite mutants if no respiration-deficient colonies were detected after 20-25 generations of growth in the presence of a high dose of euflavine. The concentration of euflavine used in each case is given in column 2 of Table 1 and the number of generations passed in presence of euflavine is given in column 3 of Table 1 . Column 4 of Table 1 shows the results obtained for 25 different strains. Even in the presence of euflavine concentrations as high as $25-50 \mu \mathrm{g} . / \mathrm{ml}$. (see column 2 of Table 1 ) about $50 \%$ of the strains were unable to give respiration-deficient mutants. The mutation was more frequent among saccharomyces strains than among other yeasts. 
Reversible inhibition of respiratory enzyme synthesis by euflavine in yeast strains unable to give petite mutants

The concentration of euflavine required to inhibit the synthesis of respiratory enzymes was measured in the following way. The organism was grown with a non-
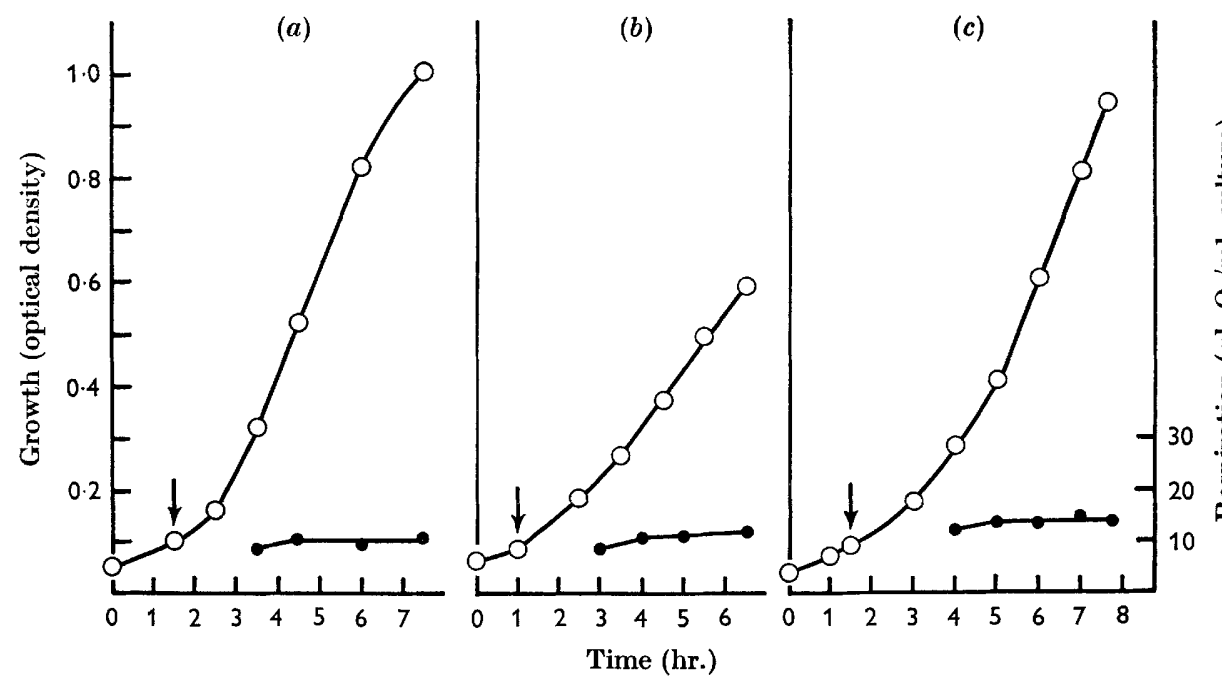

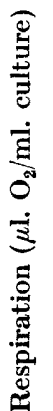

Fig. 1. Inhibition of the synthesis of the respiratory enzymes by euflavine. Organisms are growing on lactate. $O$, growth; 0 , respiration; $a$, Candida tropicalis with euflavine $2.5 \mu \mathrm{g} . / \mathrm{ml}$.; $b$, Candida monosa with euflavine $5.0 \mu \mathrm{g} . / \mathrm{ml} . ; c$, Candida pseudotropicalis with euflavine $5 \cdot 0 \mu \mathrm{g} . / \mathrm{ml}$. The time of addition of euflavine indicated by arrows.

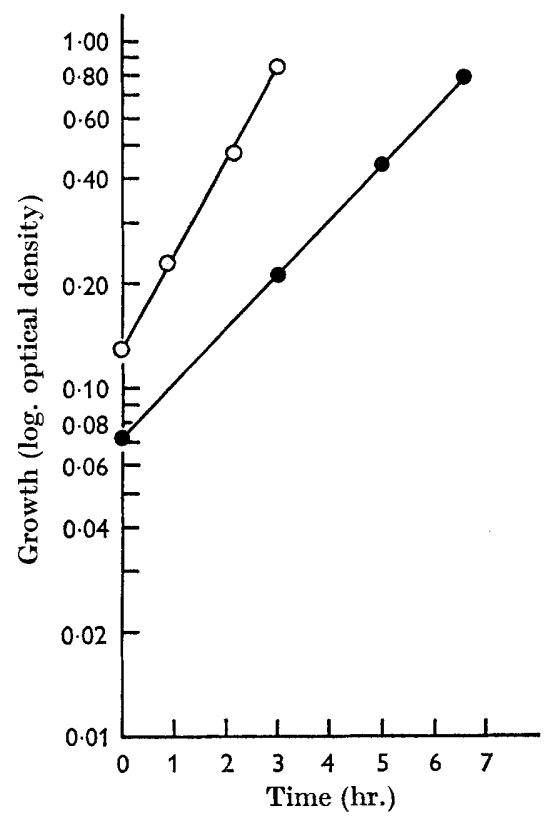

Fig. 2. Exponential growth on glucose in the presence of euflavine. $\bigcirc$, Candida tropicalis with euflavine $2.5 \mu \mathrm{g} . / \mathrm{ml}$; ; , Saccharomyces fragilis with euflavine $2.5 \mu \mathrm{g} . / \mathrm{ml}$. 
fermentable substrate (e.g. lactate, glycerol, ethanol) and euflavine was added to the culture at the beginning of the exponential phase of growth. When the concentration of euflavine inhibited the synthesis of respiratory enzymes, the rate of oxygen uptake $/ \mathrm{ml}$. culture became constant instead of increasing exponentially, and the growth became linear as a function of time. The experiment is illustrated by Fig. 1 for three different strains. In a control experiment (Fig. 2) it is shown that the same concentration of euflavine allowed exponential growth in the presence of
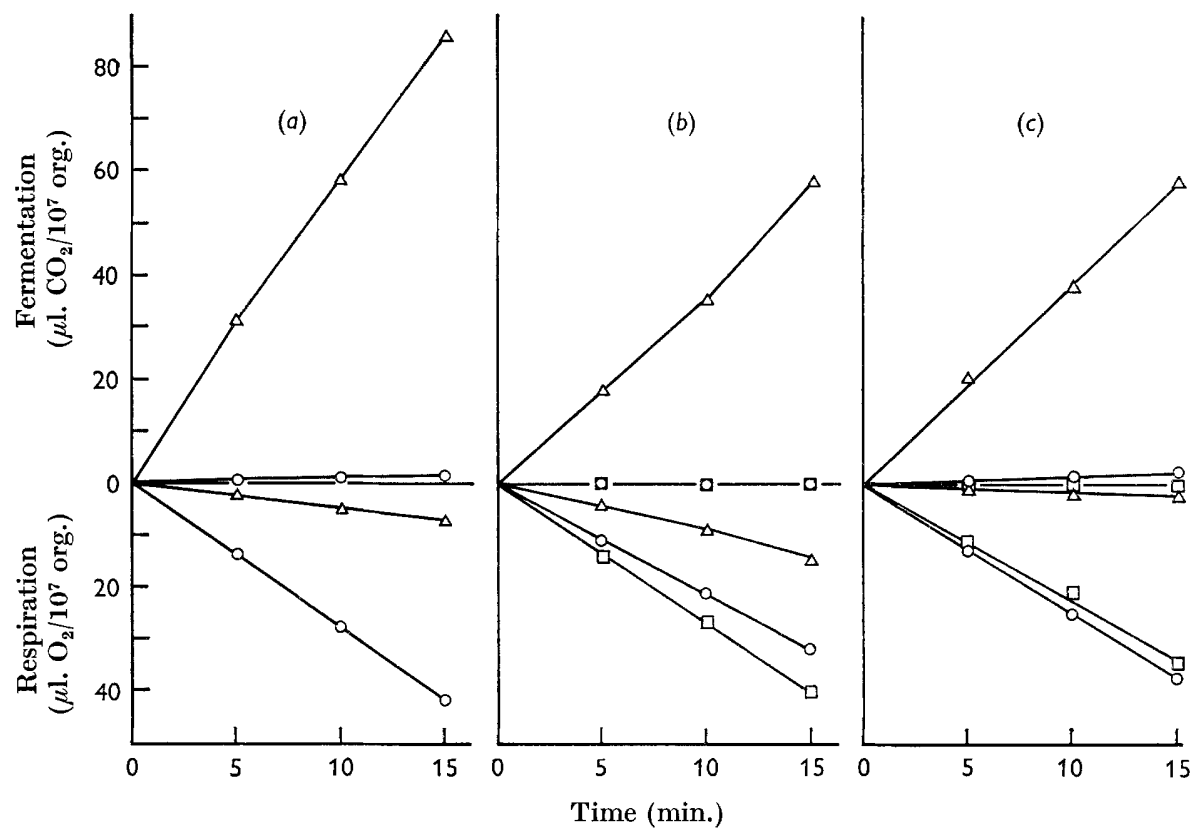

Fig. 3. Aerobic fermentation of glucose and respiration by organisms growing with and without acridines. $O$, without inhibitor; $\Delta$, euflavine, $2.5 \mu \mathrm{g} . / \mathrm{ml} . ; \square$, proflavine, $10.0 \mu \mathrm{g} . / \mathrm{ml}$; (a), Candida tropicalis; (b), Candida monosa; (c), Saccharomyces fragilis.

a fermentable substrate; under these conditions the degradation of glucose proceeded via aerobic fermentation (Fig. 3) because of the lack of respiratory enzymes. The exponential growth on glucose plus euflavine in the absence of the respiratory enzymes synthesis shows also that the petite mutation, if able to occur, would not be lethal for the yeast strain. The results for 24 strains (column 1 of Table 1 ) show that a low concentration of euflavine (maximum $10 \mu \mathrm{g} . / \mathrm{ml}$.) inhibited the biosynthesis of respiratory enzymes in strains which did not give petite mutants as well as in strains which did give petite mutants. This means, at least, that euflavine was able to enter the cells and reach the site of synthesis of respiratory enzymes even in those yeast strains which did not give respiration-deficient mutants after treatment with euflavine.

\section{Sensitivity of the site of respiratory enzymes synthesis to mutagenic and non-mutagenic acridines}

Studies by Marcovitch (1953) indicated that some acridine dyes of molecular structure closely related to euflavine were not mutagenic. We know also that the 
mutagenic acridines are the only ones able to inhibit the synthesis of respiratory enzymes in a Saccharomyces cerevisiae strain which does give petite mutants (Slonimski, 1953b). It was of interest to verify whether a non-mutagenic acridine, such as proflavine, did not inhibit the biosynthesis of respiratory enzymes in strains which are unable to give petite mutants. The aim of this experiment was to rule out the possibility of a general and non-specific inhibition of the synthesis of respiratory enzymes by acridines in strains which do not give respiration-deficient mutants.

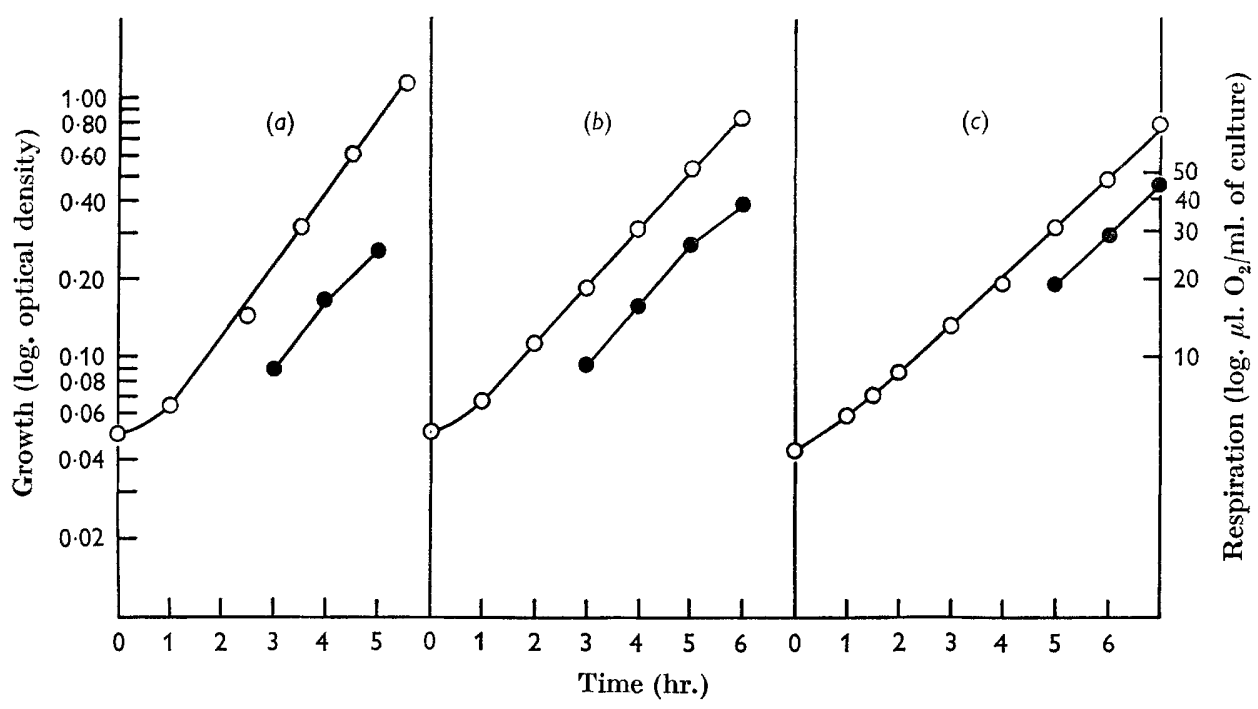

Fig. 4. Exponential growth and synthesis of respiratory enzymes in the presence of proflavine. $O$, growth; 9 , respiration; (a), Candida tropicalis; $(b)$, Candida monosa; (c), Saccharomyces fragilis.

Three different strains were treated by proflavine, a non-mutagenic acridine, and the results are shown in Fig. 4. The experiment shows that proflavine allowed exponential growth and an exponential increase of the respiration rate in the presence of a non-fermentable substrate. Therefore a non-mutagenic acridine did not inhibit the synthesis of respiratory enzymes and it may be concluded that both kinds of yeasts, able or not to give petite mutants, are endowed with the same stereochemical characteristics as far as sensitivity to acridines is concerned.

\section{Physiological function of the site sensitive to mutagenic acridines}

It is well known that petite mutants are unable to synthesize the cytochromes of types $a$ and $b$, but are still able to synthesize cytochrome $c$. It was of interest to know whether the effect of euflavine can mimic the petite mutation. Spectroscopic examination of Candida tropicalis (a strain unable to give petite mutants) grown in the presence of euflavine revealed that both cytochromes $a$ and $b$ are absent and that cytochrome $c$ was still present. Moreover, we previously observed that the biosynthesis of cytochrome $c$ in a petite mutant of Saccharomyces cerevisiae was also insensitive to the presence of euflavine (De Deken, 1961 b). One may thus 
conclude that both kinds of yeasts, able or not able to give petite mutants, have a euflavine-sensitive site which controls, in some way or another, the synthesis of cytochromes of types $a$ and $b$.

\section{The physiological characteristic common to yeast strains able to accomplish the petite mutation}

Although euflavine is apparently able to reach the same site and to inhibit this site in the same manner in all the yeast strains tested, this action may or may not be followed by the mutation. Thus the accomplishment of the mutation has to be ascribed to a property of the strain itself. This property is probably genetic, but we

Table 1. Relationship between Crabtree effect and petite mutation

\section{Organism}

Saccharomyces cerevisiae

S. chevalieri

S. fragilis

S. italicus

S. oviformis

S. pasteurianus

S. turbidans

S. carlsbergensis

Schizosaccharomyces pombe

Candida utilis

C. tropicalis

C. monosa

Trichosporon fermentans

Hansenula anomala

Debaryomyces globosus

Pichia fermentans

Schwanniomyces occidentalis

Brettanomyces lambicus

Torulopsis dattila

T. sphaerica

T. glabrata

T. colliculosa

T. sake

Nematospora coryli

Nadsonia fulvescens

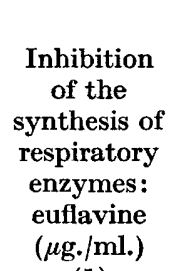

(1)

1.0

$\mathbf{2} \cdot 5$

5. 0

2.5

2.5

$\mathbf{2 \cdot 5}$

2.5

2.5

$10 \cdot 0$

$2 \cdot 5$

$5 \cdot 0$

$2 \cdot 5$

$10 \cdot 0$

$10 \cdot 0$

$\mathbf{2 \cdot 5}$

$5 \cdot 0$

$10 \cdot 0$

$2 \cdot 5$

$\mathbf{2} \cdot 5$

$5 \cdot 0$

$5 \cdot 0$

5.0
Induction of the petite mutation by euflavine

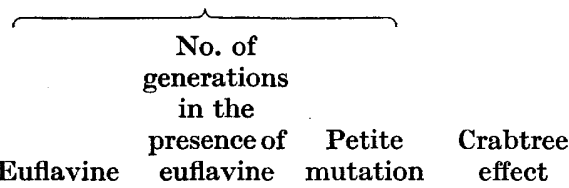

(2)

$1 \cdot 0$

$\mathbf{2 \cdot 5}$

10.0

$25 \cdot 0$

2.5

$2 \cdot 5$

2.5

$10 \cdot 0$

$2 \cdot 5$

2.5

$\left\{\begin{array}{l}25 \cdot 0 \\ 50 \cdot 0\end{array}\right.$

$25 \cdot 0$

$\left\{\begin{array}{l}10 \cdot 0 \\ 25 \cdot 0\end{array}\right.$

25.0

$\{25 \cdot 0$

$\{50 \cdot 0$

5.0

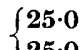

$25 \cdot 0$
$10 \cdot 0$

$10 \cdot 0$

$2 \cdot 5$

$\left\{\begin{array}{l}10 \cdot 0 \\ 25 \cdot 0\end{array}\right.$

$5 \cdot 0$

$5 \cdot 0$

25.0

$5 \cdot 0$

$10 \cdot 0$
(3)

(4)

(5)

* For some unknown reason the $\%$ of petite mutants among the population did not exceed $20 \%$ for this strain.

NoTE. It is obvious that the petite mutation would be lethal for a yeast unable to ferment glucose: strains able to ferment glucose were thus selected for this work. 
may hope that the phenotypic expression of it (i.e. a physiological property) will distinguish the strains able to give petite mutants from those not able. Since the site of synthesis of cytochromes $a$ and $b$ is sensitive to euflavine and to a regulatory system (the Crabtree effect) at least in certain strains (see De Deken, 1966), we could investigate whether the property responsible for the Crabtree effect could also be the physiological property responsible for the accomplishment of the petite mutation.

The Crabtree effect was measured for all strains as described previously (De Deken, 1966). The Crabtree effect and the petite mutation may be compared in columns 4 and 5 of Table 1 . The correlation between the two phenomena is fairly good. Among the 15 strains which exhibited the Crabtree effect, 14 gave petite mutants at low concentrations of euflavine. Among the 10 strains which showed no Crabtree effect, 8 never gave rise to respiration-deficient mutants. The two other strains (Candida monosa, Pichia fermentans) required very high doses of euflavine to bring about mutation-5 to 10 times greater than the concentration required to inhibit the synthesis of respiratory enzymes.

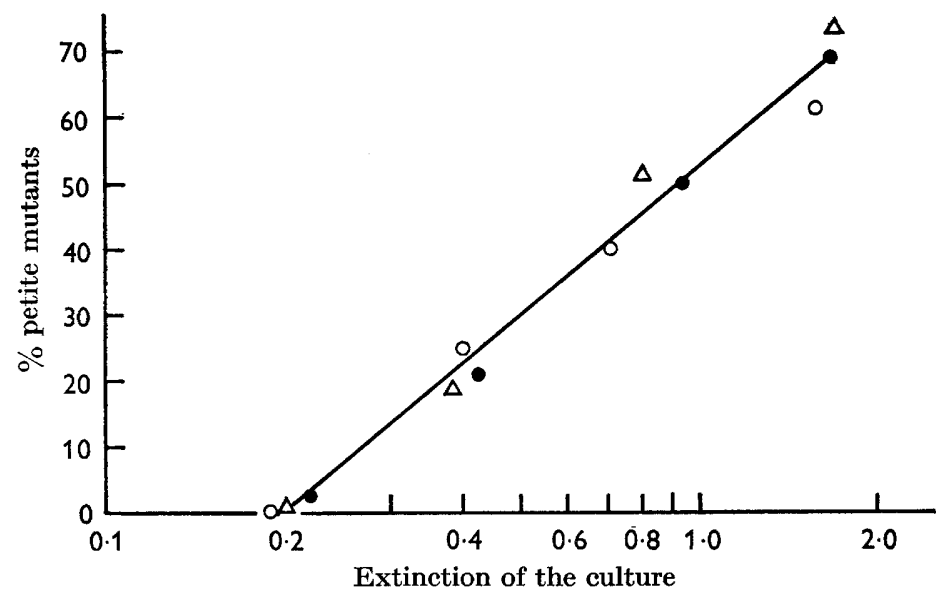

Fig. 5. Saccharomyces cerevisiae: differential rate of mutation induced by euflavine on different sources of carbon and energy, 0 , glucose; $\Delta$. galactose; $O$, lactate. Euflavine ( $1 \mu \mathrm{g} . / \mathrm{ml}$.) was added when the culture had an extinction of $0 \cdot 1$ (Beckman $\mathrm{C}$ ).

\section{Saccharomyces cerevisiae: relationship between the intensity of the Crabtree effect and the kinetics of the petite mutation}

It is possible to vary the intensity of the Crabtree effect, i.e. to vary the differential rate of respiratory enzymes synthesis, by modifying the nature of the carbon source (De Deken, 1966). The Crabtree effect is maximum with glucose (ratio 49.0), partial with galactose (ratio $\mathbf{2 \cdot 2}$ ) and of course zero with a non-fermentable substrate such as lactate. The three different media were inoculated with Saccharomyces cerevisiae normal strain and treated with euflavine. Samples of the cultures were taken during growth and plated on a glucose medium without euflavine, to determine the proportion of petite mutants among the population. The percentage of petite mutants was plotted against extinction of the culture (Fig. 5) as measured with a Beckman $\mathrm{C}$ apparatus. 


\section{DISCUSSION}

The cytoplasmic petite mutation implies that some genetic information is carried in the cytoplasm. It is reasonable to think that that this information is present in deoxyribonucleic acid located in the mitochondria (Schatz, Halsbrunner \& Tuppy, 1964). Because of the irreversible character of the cytoplasmic petite mutation, we have to consider that this mutation results from a cessation of duplication of this cytoplasmic DNA rather than from a simple modification of this DNA. We know also that the petite mutant differs from the normal strain by having a modified structure of the mitochondria (Yotsuyanagi, 1962). It is thus reasonable to assume that the mitochondrial DNA contains information for some structural proteins of the mitochondria.

If it is obvious that a number of chromosomal genes are responsible for the structure of the cytochromes $a$ and $b$ (Sherman, 1963; Sherman \& Slonimski, 1964), it is also quite possible that both the nuclear and the mitochondrial DNA are involved in the synthesis of the cytochromes $a$ and $b$. The action of chloramphenicol on Saccharomyces cerevisiae suggests that the mitochondrial DNA determines the synthesis of the insoluble cytochromes, i.e. cytochromes $a$ and $b(\operatorname{Dr} \mathrm{A}$. W. Linnane personal communication).

In the present article we came to the conclusion that euflavine mimics the petite mutation. Whether this inhibition is followed by mutation to petite or not is a characteristic of the given strain rather than a property of euflavine. The reversible inhibition of the synthesis of cytochromes $a$ and $b$ by euflavine may be understood as an interference of euflavine with the heterocatalytic activity of the mitochondrial DNA if we assume that this DNA is involved in the synthesis of the insoluble cytochromes.

We observed also that there is a correlation between the presence of the Crabtree effect in a given strain and the ability of this strain to give petite mutants, either spontaneously at a low frequency or in the presence of euflavine with a high frequency. The Crabtree effect is the phenotypic expression of a regulatory system involved in the synthesis of the cytochromes (De Deken, 1966). Therefore one can speculate that a genetic factor involved in the Crabtree effect is (at least under some conditions) an obstacle to the duplication of the DNA and helps euflavine to prevent the duplication. As a result of this situation the DNA replication becomes slower than the division rate of mitochondria and gives rise to mitochondria which lack the genetic information.

Two types of results reported in the present work seem to contradict the above hypothesis. (1) The differential rate of respiratory enzymes synthesis does not affect the mutation rate to petite. This means that the phenotypic expression of the Crabtree effect does not affect the rate of mutation but that the presence of the genetic elements involved in this regulatory system is important. (2) Two strains which show no Crabtree effect were able to give petite mutants. This may mean that the presence of only one genetic element involved in the regulatory systemeither the moderating element or the acceptor site of the regulatory system--may be sufficient for the accomplishment of the petite mutation.

We are grateful to Professor Th. Doehaerd for valuable suggestions about the spectroscopic techniques. We are also deeply indebted to Mr J. Dewets who made 
the Dewar flask. We wish to thank Dr E. Dubnau for helping to prepare the manuscript.

\section{REFERENCES}

Albert, A. (1951). The Acridines, Their Preparation, Physical, Chemical and Biological Properties and Uses. London: Edward Arnold and Co.

De Deken, R. H. (1961a). The dissociation of phenotypic and inheritable effects of euflavine in yeast. Exp. Cell Res. 24, 145.

De Deken, R. H. (1961b). Propriétés du site sensible à l'euflavine chez la levure. Archs int. Physiol. Biochim. 69, 746.

De Deken, R. H. (1966). The Crabtree effect: a regulatory system in yeast. J. gen. Microbiol. 44, 149.

Ephrussi, B., Hottinguer, H. \& Chimenes, A. M. (1949). Action de l'acriflavine sur les levures. I. La mutation 'petite colonie'. Ann. Inst. Pasteur, 76, 351.

Linnane, A. W. \& Still, J. L. (1956). A re-examination of some problems of petite yeast. Aust. J. Sci. 18, 165.

Marcovitch, H. (1953). Rapports entre la structure des acridines et leur activité en tant qu'agents inducteurs de mutants respiratoires chez la levure. Ann. Inst. Pasteur, 85, 199.

Schatz, G., Halsbrunner, E. \& Tuppy, H. (1964). Deoxyribonucleic acid associated with yeast mitochondria. Biochem. biophys. Res. Commun. 15, $12 \%$.

Sherman, F. (1963). Respiration-deficient mutants of yeast. I. Genetics. Genetics, 48, 375.

Sherman, F. \& Slonimski, P. P. (1964). Respiration-deficient mutants of yeast. II. Biochemistry. Biochim. biophys. Acta, 90, 1.

Slonimski, P. P. (1953a). Formation des enzymes respiratoires chez la levure. Paris: Masson.

Slonimski, P. P. (1953b). A specific relation between enzymic adaptation and cytoplasmic mutation. In Adaptation in Microorganisms, Symp. Soc. gen. Microbiol. 3, 76.

Slonimski, P. P. \& Ephrussi, B. (1949). Action de l'acriflavine sur les levures. V. Le système des cytochromes des mutants 'petite colonie'. Ann. Inst. Pasteur, 77, 47.

Slonimski, P. P. \& Hirsch, H. M. (1952). Nouvelles données sur la constitution enzymatique du mutant 'petite colonie' de Saccharomyces cerevisiae. C.r. hebd. Séanc. Acad. Sci., Paris, 235, 741.

Yotsuyanagr, Y. (1962). Etudes sur la chondriome de la levure. II. Chondriomes des mutants à déficience respiratoire. J. ultrastruct. Res. 7, 141. 